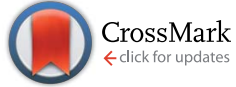

Cite this: RSC Adv., 2017, 7, 3043

Received 20th October 2016 Accepted 5th December 2016

DOI: 10.1039/c6ra25565e

www.rsc.org/advances

\section{Highly sensitive and selective complexation based voltammetric methods for the analysis of rabeprazole sodium in real samples $\uparrow$}

\begin{abstract}
Pakinaz Y. Khashaba, ${ }^{\text {ab }}$ Hassan Refat H. Ali ${ }^{a}$ and Mohamed M. El-Wekil ${ }^{\star a}$
The effect of adding transition metals to the electrolyte containing proton pump inhibitors, such as rabeprazole sodium (RAB sodium), on the voltammetric response of pencil graphite electrode was studied. Both square-wave adsorptive stripping voltammetry (SWAdSV) and cyclic voltammetry (CV) were utilized to elucidate and confirm the possible complexation reaction that could occur between RAB sodium and cobalt as a transition metal. The current signal due to the oxidation process was a function of the concentration of RAB sodium, $\mathrm{pH}$ of the medium, cobalt concentration, scan rate, frequency, and deposition time at the electrode surface. This phenomenon could be used for the determination of RAB sodium using CV and SWAdSV. The oxidation peak current linearly varied with the concentration over the range of $0.05-9 \times 10^{-9} \mathrm{M}$ and $0.2-8.5 \times 10^{-7} \mathrm{M}$ for SWAdSV and CV, respectively. The limits of detection were found to be $0.015 \times 10^{-9} \mathrm{M}$ and $0.06 \times 10^{-7} \mathrm{M}$ for SWAdSV and $\mathrm{CV}$, respectively. The validity of using these methods for the determination of RAB sodium in its pharmaceutical formulation and human urine samples was evaluated.
\end{abstract}

\section{Introduction}

Rabeprazole sodium is a member of proton pump inhibitor antiulcer drugs. It is a benzimidazole derivative that is used in the treatment of peptic ulcers and reflux esophagitis. ${ }^{1}$ Its efficacy as an antiulcer and antisecretory agent has been well established. Previously, different analytical techniques, such as spectrophotometry, ${ }^{2-4}$ spectrofluorometry, ${ }^{5}$ thin layer chromatography, ${ }^{2}$ and high performance liquid chromatography, ${ }^{2,6-10}$ have been used to determine RAB sodium. These techniques usually require complicated sample pretreatment, which is laborious and time-consuming. To date, only two electrochemical methods $\mathbf{s}^{\mathbf{4 1 1}}$ have been reported for the determination of RAB sodium in the bulk powder and tablets using a hanging mercury electrode and glassy carbon electrode. The first electrode is unsafe and has toxic effects, whereas the second electrode usually requires several pretreatment procedures prior to use.

Voltammetry has been widely used for the investigation of redox reactions and analysis of organic or inorganic substances using various available electrodes. Due to their low ${ }^{a}$ Department of Pharmaceutical Analytical Chemistry, Faculty of Pharmacy, Assiut
University, Egypt. E-mail: mohamed.mohamoud@ymail.com
${ }^{b}$ Department of Pharmaceutical Analytical Chemistry, Faculty of Pharmacy, Deraya
University, El-Minya, Egypt

$\uparrow$ Electronic supplementary information (ESI) available. See DOI: 10.1039/c6ra25565e background current, wide potential window, chemical inertness, low-cost, and suitability for various sensing and detection applications, several forms of carbon electrodes are available for electroanalytical applications. ${ }^{\mathbf{1 2 - 1 4}}$ Among these, pencil graphite electrode (PGE) is one of the key electrodes that has been applied to cathodic or anodic stripping voltammetry for the detection of trace metals, ${ }^{15} \mathrm{DNA},{ }^{\mathbf{1 6}, 17} \mathrm{immu}$ noassay, ${ }^{18}$ and certain pharmaceuticals. ${ }^{19}$ The utilization of pencil leads as electrodes is well documented..$^{20-27}$ The pencil "lead" is actually a mixture of graphite, wax, and clay, the proportions of which impart different properties to the pencil with the increasing amounts of clay making the pencil harder, hence the designation ' $\mathrm{H}$ '. Increasing levels of graphite make the pencil softer and their marks darker or black and so the designation ' $\mathrm{B}$ '. For example, one of the darkest generally available pencils, the $6 \mathrm{~B}$, is $84 \%$ graphite, $10 \%$ clay, and $5 \%$ wax, compared to the common lighter HB or No. 2 pencil, which has a composition of $68 \%$ graphite, $26 \%$ clay, and $5 \%$ wax. ${ }^{28}$ Commonly, pencil has been directly used as the working electrode itself; ${ }^{20-27}$ however, only recently, the possibility of using pencils to draw electrodes onto a suitable substrate has been reported. ${ }^{29}$ This type of electrode offers high electrochemical reactivity, high electrical conductivity, good mechanical rigidity, low-cost, simple technology, ease of modification, renewable, low background current, and miniaturization. This type of electrode has a larger active surface area and is, therefore, able to detect low concentrations of the analyte. 
The use of metal complexation was effective in increasing the hydrophobicity of the drug in the bulk solution and hence increasing the attraction to the electrode surface. ${ }^{30}$ Thus, the aim of the current study was to develop simple, sensitive, and reproducible complexation based methods to quantify the cited drug in its pharmaceutical formulation and spiked human urine for the first time.

\section{Experimental}

\subsection{Pharmaceuticals}

RAB sodium was supplied as a gift from Global Napi, $6^{\text {th }}$ October city, Giza, Egypt. Rabicid® tablets (Sigma, Quesna, ElMenoufia, Egypt) were labeled to contain $40 \mathrm{mg}$ RAB sodium. Domperidone was supplied as a gift from EIPICO, $10^{\text {th }}$ Ramadan city, El-Sharquia, Egypt. Aceclofenac, tinidazole, and clarithromycin were obtained as gifts from NODCAR, El-Giza, Egypt. Doxycycline was supplied as a gift from CID, Assiut, Egypt.

\subsection{Reagents}

Methanol was purchased from Fisher Scientific Limited, United Kingdom. Double distilled water was used throughout this work. Cobalt nitrate, ferric chloride, nickel sulphate, copper sulphate, and uric acid were purchased from Sigma-Aldrich co. Ltd., Steinheim, Germany. Glacial acetic acid, phosphoric acid, boric acid, and ascorbic acid were purchased from El Nasr Pharmaceutical Chemicals Co., Egypt.

Britton-Robinson buffer (B.R.) was used as a supporting electrolyte (equal volumes of $0.04 \mathrm{M}$ acetic acid, $0.04 \mathrm{M}$ phosphoric acid, and $0.04 \mathrm{M}$ acetic acid, adjusted to a desired $\mathrm{pH}$ by $2 \mathrm{~N} \mathrm{NaOH}$ ).

\subsection{Instrumentation}

A Princeton VersaSTAT MC (VersaSTAT 3, Model RE-1, Princeton Applied Research, AMETEK, USA) connected to a threeelectrode cell was used for the electrochemical measurements. In all the measurements, the reference electrode was $\mathrm{Ag} / \mathrm{AgCl}$ $(3 \mathrm{M} \mathrm{KCl})$, the auxiliary electrode was a platinum wire, and the working electrode was a PGE. A Pentel pencil, Model P205 (Japan), was used as a holder for the pencil lead. Electrical contact with the lead was achieved by soldering a metallic wire to the metallic part that holds the lead in place inside the pencil. Unless stated otherwise, the pencil was fixed such that about $3 \mathrm{~mm}$ of its length was immersed in the solution. Measurements were performed in a $10 \mathrm{~mL}$ glass cell containing $6 \mathrm{~mL}$ of the supporting electrolyte solution. Stirring was achieved with a magnetic stirring bar.

The $\mathrm{pH}$ values of the solutions were measured using a Hanna pH meter (Hanna Instruments Brazil, São Paulo, Brazil) with a combined electrode. The solutions were sonicated using a Bransonic ultrasonic cleaner, Branson UL Transonics Corporation, Eagle Road, Danbury, CT 06813, USA. Shimadzu UV-vis Spectrophotometer, UV-1800 was used to assess the complexation between RAB sodium and cobalt.

\subsection{Preparation of the standard solutions}

The standard stock solution of RAB sodium $\left(1 \times 10^{-3} \mathrm{M}\right)$ was prepared by dissolving an accurate amount of RAB sodium in double distilled water. The stock solution was stable when stored in a refrigerator at $4{ }^{\circ} \mathrm{C}$ for about 2 months.

\subsection{Sample preparation}

The contents of ten tablets were accurately weighed, finely powdered, and thoroughly mixed in a mortar. Portions equivalent to about $1 \times 10^{-3} \mathrm{M}$ of RAB sodium were accurately weighed and dissolved in a $20 \mathrm{~mL}$ methanol. The contents were sonicated for 20 minutes to ensure complete solubility. The filtrate was transferred to a $100 \mathrm{~mL}$ calibrated flask and diluted to a final volume with double distilled water. Appropriate working solutions were prepared by taking suitable aliquots from these stock solutions and diluting them with the B.R. buffer solutions ( $\mathrm{pH}=7.0)$.

Drug-free human urine samples were obtained from two healthy and non-smoking volunteers of different age and sex (after obtaining their written consent). The samples were stored in the refrigerator $\left(-20^{\circ} \mathrm{C}\right)$ and analyzed on the next day after collection without any further pretreatment. One milliliter of the corresponding urine sample was pipetted into a $25 \mathrm{~mL}$ calibrated flask and filled with the buffer solution to the mark. The experimental protocol was conducted according to the Egyptian regulations and approved by the Institutional Human Ethics Committee, Assiut University, Assiut, Egypt. Informed consents were obtained from the human participants for this study.

\subsection{General procedure}

The PGE surface was polished and pretreated by applying a potential of $+1.30 \mathrm{~V}$ for $30 \mathrm{~s}$ in the blank supporting electrolyte without stirring to increase the hydrophilic properties of the electrode surface via the introduction of oxygenated functionalities. Each measurement was performed using a new pencil surface in a glass cell containing $6 \mathrm{~mL}$ of B.R. buffer $(\mathrm{pH}=7.0)$. The SWAdSV and CV were obtained after the addition of drug and $65 \mu \mathrm{M}$ cobalt nitrate.

The optimum conditions for $\mathrm{CV}$ were found to be the adsorption time $=300$ seconds, adsorption potential $=0 \mathrm{~V}$, and scan rate $=150 \mathrm{mV} \mathrm{s}^{-1}$, whereas those for SWAdSV were found to be the adsorption potential $=-0.4 \mathrm{~V}$, frequency $=300 \mathrm{~Hz}$, step potential $=10 \mathrm{mV}$, and potential amplitude $=60 \mathrm{mV}$.

\section{Results and discussions}

\subsection{Electrochemical characterization of the PGE using standard potassium ferricyanide system}

Prior to voltammetric analysis, the PGE was evaluated. The CV was obtained using PGE wetted with $0.5 \mathrm{M} \mathrm{KCl}$, where no voltammetric peaks were obtained. Thus, no electroactive interfering species were appreciably released by all graphite sticks. Furthermore, the CV was obtained again after wetting PGE with a $10 \mathrm{mM}$ potassium ferricyanide in a $0.5 \mathrm{M} \mathrm{KCl}$, where a redox 


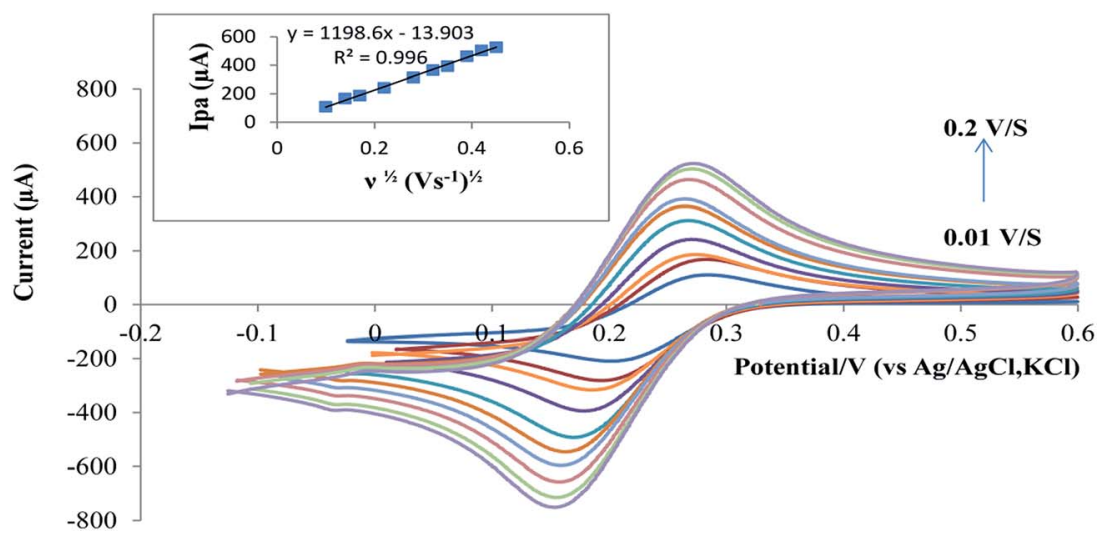

Fig. 1 The electroactive surface area of the electrode evaluated by CV.

peak potential difference was obtained as $75 \mathrm{mV}$. This shows the electroactivity of the PGE.

Randles-Sevcik equation for a reversible process ${ }^{31}$ was used to estimate the effective surface area of the PGE $\left(A_{\text {eff }} \mathrm{mm}^{2}\right)$ immersed in a $10 \mathrm{mM}$ potassium ferricyanide and a $0.5 \mathrm{M} \mathrm{KCl}$.

$$
I_{\mathrm{pa}}=\left(2.69 \times 10^{5}\right) n^{2 / 3} A_{\mathrm{eff}} D^{1 / 2} \nu^{1 / 2} C^{0}
$$

where $D$ and $C^{0}$ are the diffusion coefficient and bulk concentration of the redox probe, respectively. The $A_{\text {eff }}$ was calculated to be $16.2 \mathrm{~mm}^{2}$ (Fig. 1).

\subsection{Investigation of the electrochemical behavior of RAB sodium using CV and SWAdSV}

The electrochemical behavior of RAB-cobalt complex was investigated using three different types of carbon-based electrodes: bare glassy carbon electrode (GCE), carbon paste electrode (CPE), and pencil graphite electrode (PGE). The best results were obtained with PGE (Fig. 1S $\dagger$ ).

The CV and SWAdSV are presented in Fig. 2A and B, respectively. The $\mathrm{CV}$ of $\mathrm{RAB}$ sodium has displayed only a sole well irreversible anodic peak at $+1.15 \mathrm{~V}$, which suggests that the oxidation of RAB sodium is irreversible.

\subsection{Parameters affecting the electrochemical oxidation process}

3.3.1. The effect of $\mathbf{p H}$. The electro-oxidation of $6.5 \times$ $10^{-7}$ M RAB sodium was studied in the presence of B.R., acetate, and phosphate buffers as the supporting electrolytes by $\mathrm{CV}$ and SWAdSV (Fig. 2S $\dagger$ ). Within the range of pH 3.0-11.0, B.R. buffer was superior to other supporting electrolytes. Hence, B.R. buffer was chosen as the supporting electrolyte throughout this study. Sharp oxidation peaks were obtained only in the $\mathrm{pH}$ range 5.09.0 (Fig. 3a). On increasing the $\mathrm{pH}$ of the solution, the oxidation peak current increased up to $\mathrm{pH}$ 7.0, and then continuously decreased until $\mathrm{pH}$ 9.0. The peak potential shifted towards a lower potential with the increasing $\mathrm{pH}$. From the plot of the potential versus $\mathrm{pH}$, it could be noted that the peak intensity decreased at higher $\mathrm{pH}$ values. This could be attributed to the formation of cobalt hydroxide at alkaline $\mathrm{pH}$. The optimal result with respect to sensitivity accompanied by a sharper response was obtained at $\mathrm{pH}=7.0$; therefore, this $\mathrm{pH}$ was selected for further experiments.
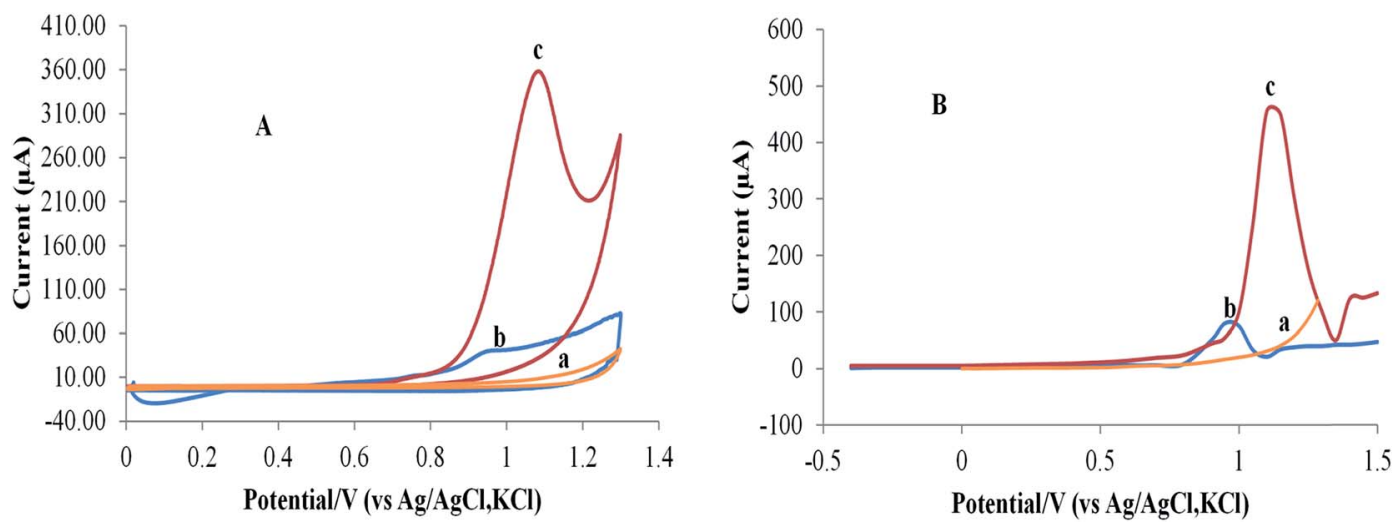

Fig. 2 (A) The CV of blank (a), $65 \times 10^{-6}$ M RAB sodium only (b), $6.5 \times 10^{-7}$ M RAB sodium with $65 \mu M$ cobalt nitrate (c). (B) The SWAdSV of blank (a), $65 \times 10^{-6}$ M RAB sodium only (b), $6.5 \times 10^{-9}$ M RAB sodium with $65 \mu$ M cobalt nitrate (c). 


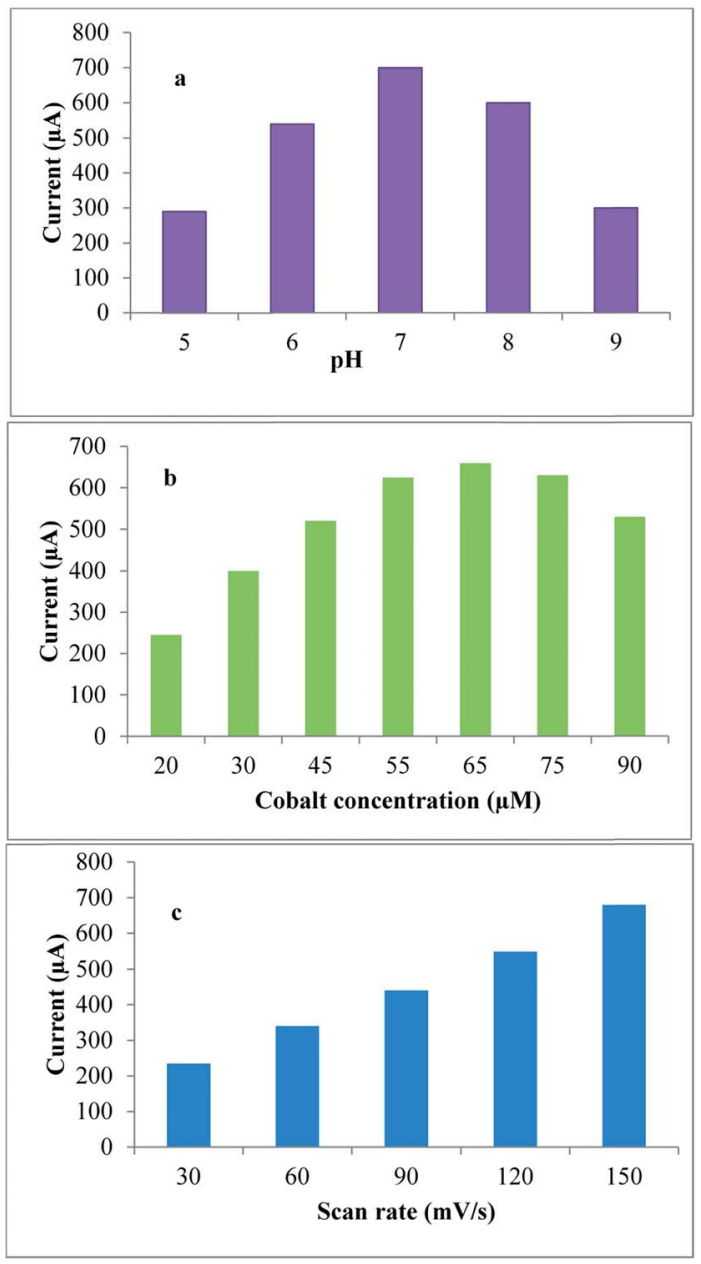

Fig. 3 (a) Relationship between peak current and $\mathrm{pH}$, (b) plot relationship between peak current and cobalt concentration and (c) plot relationship between peak current and scan rate.

3.3.2. Influence of the metal type and concentration. Several metal ions, $\mathrm{Co}^{2+}, \mathrm{Cu}^{2+}, \mathrm{Fe}^{3+}, \mathrm{Cr}^{3+}$, and $\mathrm{Cd}^{2+}$, were evaluated and the most satisfactory results in terms of peak shape were obtained with $\mathrm{Co}^{2+}$. Accordingly, different concentrations of $\mathrm{Co}^{2+}$ were studied. The optimal results were obtained with $65 \mu \mathrm{M}$ of $\mathrm{Co}^{2+}$ solution (Fig. $3 \mathrm{~b}$ ). For the sake of improving the sensitivity of the method, the responses of current using the electrodeposition of $\mathrm{Co}^{2+}$ on PGE followed by the complexation with RAB sodium and direct complexation between the drug and metal without electrodeposition were compared (Fig. 3S†). Obviously, the second approach has shown far better sensitivity. This could be attributed to the higher hydrophobicity of the drug in the bulk solution after complexation and increase in the oxidation of the complex on the surface of PGE.

3.3.3. Influence of the initial deposition potential and time. The effect of adsorption potential and time on the anodic peak current of RAB sodium was studied at various adsorption potentials between $-0.4 \mathrm{~V}$ and $+1.3 \mathrm{~V}$ for SWAdSV and from 0 to +1.3 for $\mathrm{CV}$ in the B.R. buffer ( $\mathrm{pH}$ 7.0) in the presence of $65 \mu \mathrm{M}$ of cobalt nitrate. The maximum peak current is obtained at the adsorption potential of $-0.4 \mathrm{~V}$ and time of 300 seconds for SWAdSV, and for $\mathrm{CV}$, it is obtained at $-0.9 \mathrm{~V}$ and 240 seconds (Fig. $4 \mathrm{~S}$ and $5 \mathrm{~S} \dagger$ ).

3.3.4. Influence of the scan rate on the CV. Fig. $3 \mathrm{c}$ shows the effect of scan rate $(\nu)$ in the range from 30 to $150 \mathrm{mV} \mathrm{s}^{-1}$ on the $\mathrm{CV}$ response of RAB sodium in the B.R. buffer $(\mathrm{pH}$ 7.0) containing $65 \mu \mathrm{M}$ of cobalt nitrate. With the increasing scan rates, the anodic peak slightly shifted to the positive potential side. The peak current remarkably increased with the increasing scan rates. From the value of the slope, it can be

Table 1 Quantitative parameters of the proposed CV and SWAdSV methods for the determination of RAB sodium in pure forms

\begin{tabular}{lll}
\hline Parameters & CV & SWAdSV \\
\hline Measured potential (volts) & 1.15 & 1.15 \\
Linearity & $0.9-8.5$ & $0.9-9.0$ \\
Correlation coefficient $\left(r \pm \mathrm{SD}^{a}\right)$ & $0.9995 \pm 0.001$ & $0.9994 \pm 0.009$ \\
Intercept $\left( \pm \mathrm{SD}^{a}\right)$ & $125.4 \pm 1.9$ & $-9.0 \pm 0.2$ \\
Slope $\left( \pm \mathrm{SD}^{a}\right)$ & $102.6 \pm 1.1$ & $35.6 \pm 0.6$ \\
$\mathrm{LOD}^{b}$ & 0.061 & 0.015 \\
$\mathrm{LOQ}^{b}$ & 0.185 & 0.045
\end{tabular}

${ }^{a}$ Average of five replicates. ${ }^{b}$ Concentration in SWAdSV expressed as $10^{-9} \mathrm{M}$, whereas that in CV expressed as $10^{-7} \mathrm{M}$.
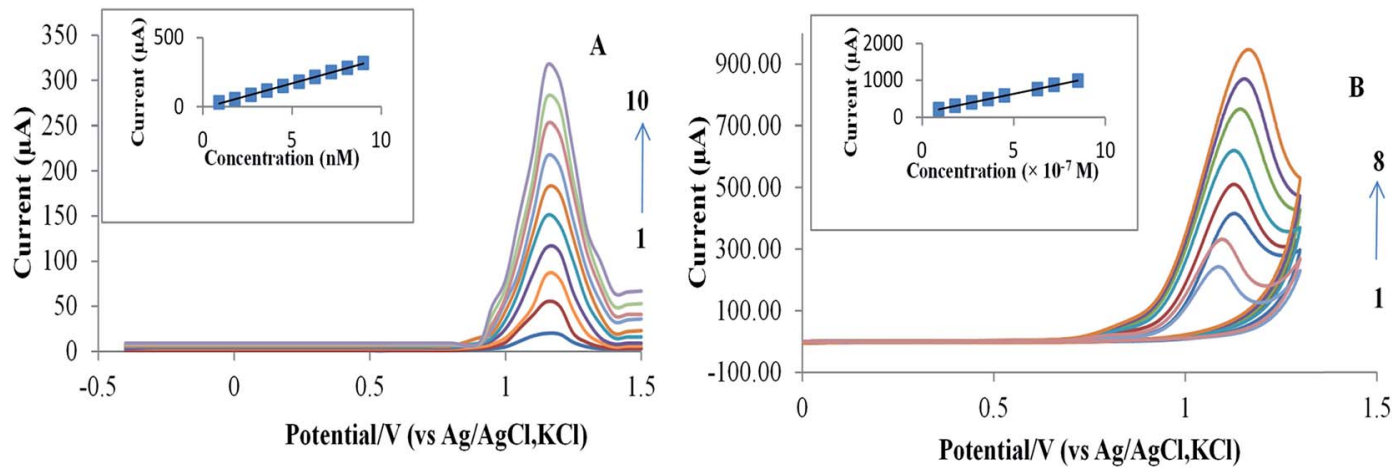

Fig. 4 The effect of different concentrations of RAB sodium on SWAdSV (A) $\left(2-9 \times 10^{-9} \mathrm{M}\right)(1-11)$ and CV (B) $\left(2-8.5 \times 10^{-7} \mathrm{M}\right)(1-8)$ in B.R. buffer $(\mathrm{pH}=7.0)$ containing $65 \mu \mathrm{M}$. Insets are the calibration curves. 
deduced that the electrochemical oxidation process of RAB sodium is diffusion-controlled process with an adsorption contribution. For an adsorption-controlled electrode reaction, the following equation could apply: ${ }^{32}$

$$
I_{\mathrm{pa}}=\frac{n F Q \nu}{4 R T}
$$

where, $Q$ is the peak area that could be obtained under a given scan rate, $\nu$ is the scan rate, and $F, R$ and $T$ are the constants. From the slope of $I_{\mathrm{p}} v s$. $\nu$, the electron-transfer number $(n)$ that was involved in the electrode reaction of RAB sodium was calculated to be 2 .
3.3.5. Effect of frequency, step-potential, and pulse amplitude. The effect of frequency was studied in the range of 10-350 Hz. A linear relationship was obtained between the peak current and frequency of the signal up to $300 \mathrm{~Hz}$ due to the increase in the effective scan rate, whereas at higher values of frequency, the peak heights decreased. Hence, the frequency of $300 \mathrm{~Hz}$ was chosen for the entire analysis by SWAdSV method (Fig. 6S $\dagger$ ). The influence of step potential was investigated between 1 and $20 \mathrm{mV}$. Best results were obtained at $10 \mathrm{mV}$. Pulse amplitude was examined in the range from 5 to $70 \mathrm{mV}$. Peak heights increased upon an increase in the pulse amplitude up to $60 \mathrm{mV}$, and at higher

Table 2 Analysis of Rabicid $®$ tablets by the standard addition method and precision of the proposed method

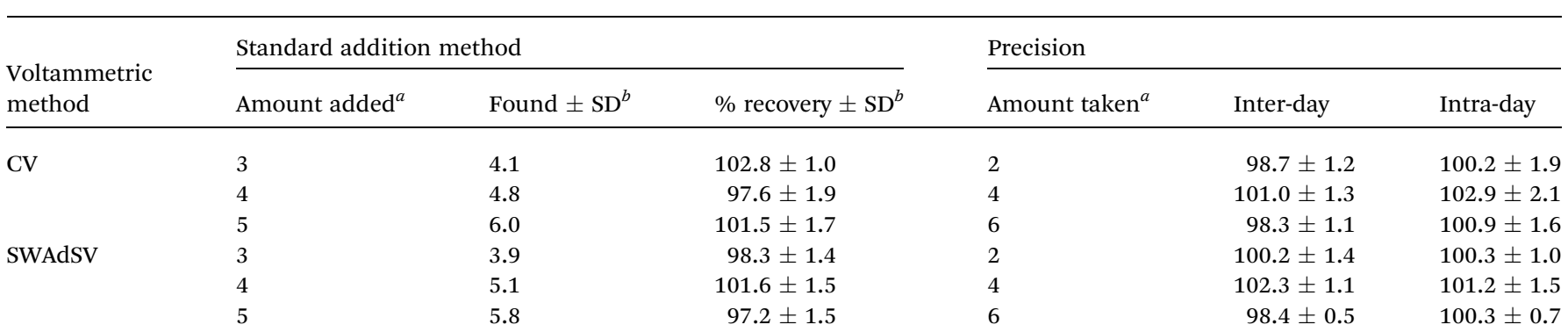

${ }^{a}$ Concentration in SWAdSV expressed as $10^{-9} \mathrm{M}$, whereas that in CV expressed as $10^{-7} \mathrm{M} .{ }^{b}$ Average of five replicates.

Table 3 The influence of the potential components on the voltammetric response of RAB

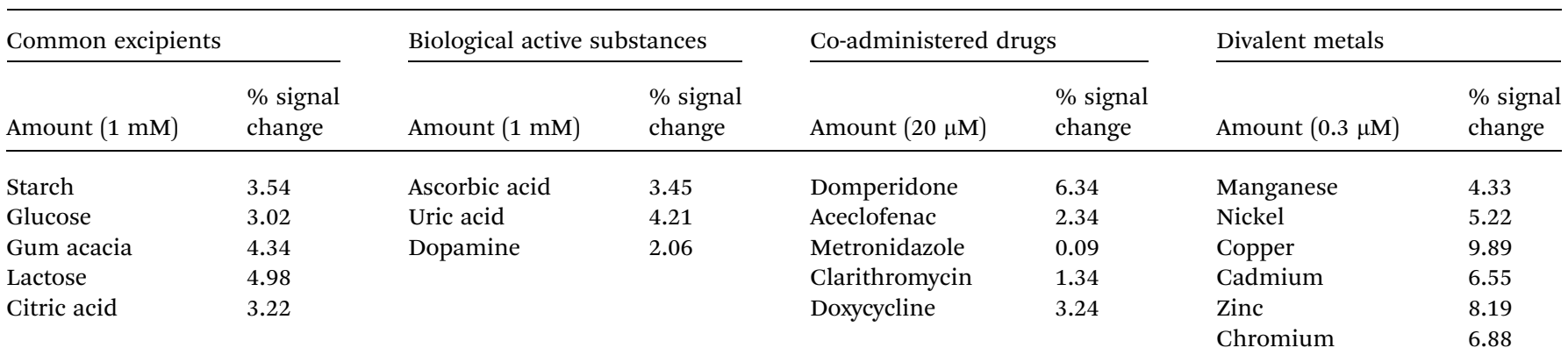
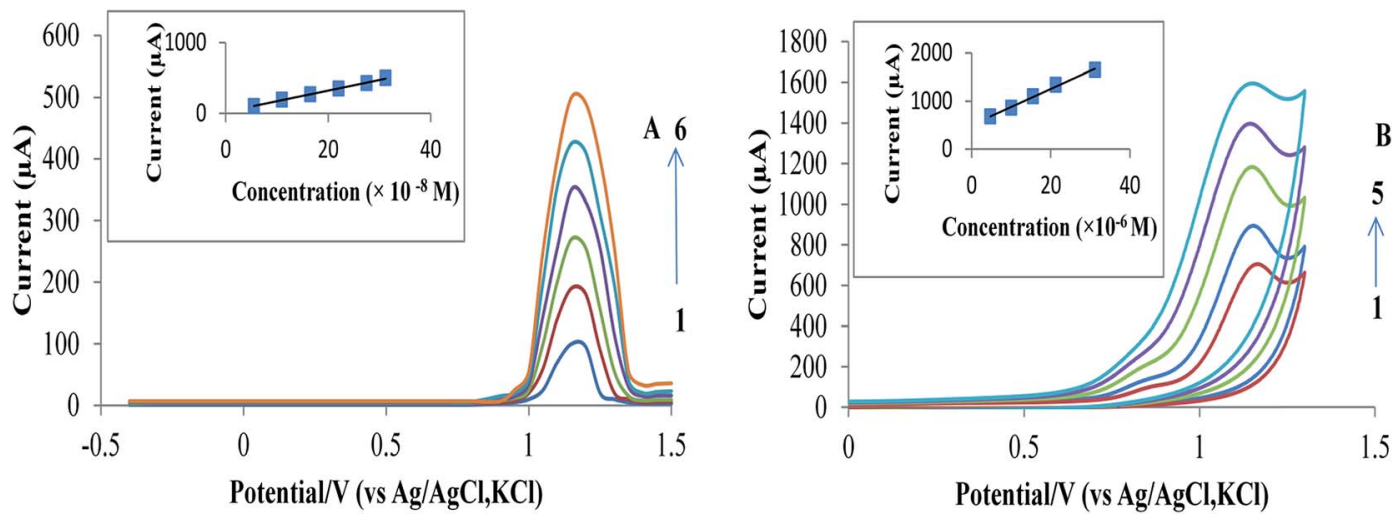

Fig. 5 The effect of different concentrations of RAB sodium on SWAdSV (A) $\left(5-31 \times 10^{-8} \mathrm{M}\right)(1-6)$ and CV (B) $\left(5-31 \times 10^{-6} \mathrm{M}\right)(1-5)$ in model urine of volunteer $\mathrm{A}(\mathrm{pH}=7.0)$ containing $65 \mu \mathrm{M}$ cobalt nitrate. Insets are the calibration curves. 
Table 4 Comparison between the proposed methods and reported methods

\begin{tabular}{|c|c|c|c|c|}
\hline Reported methods & Linear range $\left(\mu \mathrm{g} \mathrm{mL}^{-1}\right)$ & $\mathrm{LOD}\left(\mu \mathrm{g} \mathrm{mL}^{-1}\right)$ & $\mathrm{LOQ}\left(\mu \mathrm{g} \mathrm{mL}^{-1}\right)$ & Reference \\
\hline \multirow[t]{3}{*}{ Spectrophotometry } & $10-30$ & 0.019 & 0.058 & 2 \\
\hline & $5-40$ & 0.19 & 0.57 & 3 \\
\hline & $4.5-40$ & - & - & 4 \\
\hline Spectrofluorometry & $10-85$ & 2.99 & 9.07 & 5 \\
\hline HPTLC & $0.5-2.5$ & 0.1 & 0.31 & 2 \\
\hline \multirow[t]{6}{*}{ HPLC } & $4-20$ & 0.025 & 0.076 & 2 \\
\hline & $0.02-1.5$ & - & 0.02 & 6 \\
\hline & $0.00015-0.1$ & - & - & 7 \\
\hline & $0.00014-0.096$ & - & - & 8 \\
\hline & $0.02-1$ & - & - & 9 \\
\hline & $0.001-0.5$ & - & - & 10 \\
\hline Polarography & $0.6-8$ & - & - & 4 \\
\hline SWV & $0.3-9$ & - & - & \\
\hline DPV & $1-20$ & 0.4 & 1.0 & 11 \\
\hline SWV & $0.9-9.0 \times 10^{-9} \mathrm{M}$ & $0.015 \times 10^{-9} \mathrm{M}$ & $0.045 \times 10^{-9} \mathrm{M}$ & The present work \\
\hline $\mathrm{CV}$ & $0.9-8.5 \times 10^{-7} \mathrm{M}$ & $0.061 \times 10^{-7} \mathrm{M}$ & $0.185 \times 10^{-7} \mathrm{M}$ & \\
\hline
\end{tabular}

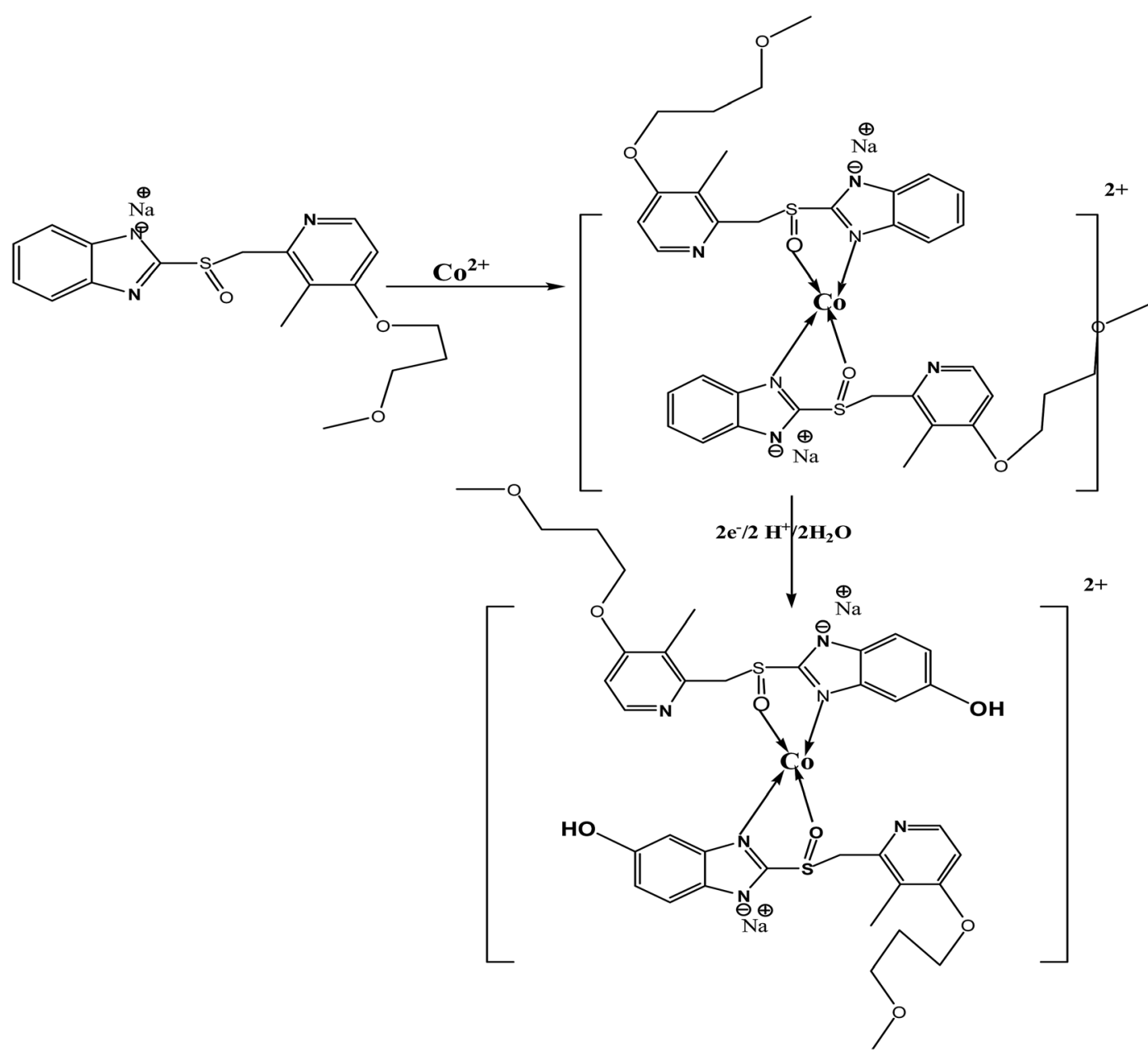

Scheme 1 The proposed complexation and oxidation mechanisms for RAB sodium. 
values, the peak shape was distorted. Thus, $60 \mathrm{mV}$ was chosen as the optimal pulse amplitude for the proposed SWAdSV method.

\section{Method validation}

\subsection{Linearity, LOD, and LOQ}

Fig. 4A and B for the proposed SWAdSV and CV methods, respectively, show linear calibration plots over the concentration range under the optimal conditions. Table 1 shows good values for the correlation coefficient $(r)$ with a small intercept and a small value of the standard deviation and \% relative standard deviation that indicate high accuracy and precision of the proposed methods. The limits of detection (LOD) and quantitation (LOQ) were calculated using the following equations: ${ }^{33} \mathrm{LOD}=3.3 s / S$, and $\mathrm{LOQ}=10 \mathrm{~s} / S$, where " $s$ " is the mean of standard deviation of the intercept and " $S$ " is the mean of the slope of the calibration curve. The LOD and LOQ are presented in Table 1. Obviously, the values of LOD and LOQ indicate that the SWAdSV and CV are very sensitive for the RAB sodium analysis.

\subsection{Accuracy and precision}

The accuracy of the method was determined by standard addition method and calculating the recovery percentages. Moreover, the results of the inter-day and intra-day precision prove the precision of the proposed methods (Table 2).

\subsection{Selectivity of the proposed method}

The effects of common excipients, co-administered drugs, biologically active compounds, and divalent metals have been evaluated (Table 3). Clearly, a \% signal change of $6.5 \times 10^{-9} \mathrm{M}$ RAB sodium upon the addition of these potential interfering substances does not appreciably change. This could indicate the selectivity of the method and hence its suitability for the determination of pharmaceuticals in the complex matrices.

\subsection{Application of the proposed methods to real samples}

The proposed methods were applied for the determination of RAB sodium in the tablets using standard addition method (Table 2). The urine samples were collected from two healthy and non-smoking volunteers of different age and sex. The samples were analyzed by the proposed methods after simple dilution with B.R. buffer $(\mathrm{pH}=7.0)$. The average results of the three measurements, expressed as a confidence interval for 95\% probability for two volunteers, obtained by the proposed methods are summarized in Tables $1 \mathrm{~S}$ and $2 \mathrm{~S}$. $\dagger$ As an illustrative example of the analysis of the model human urine sample, the obtained voltammograms for volunteer A are depicted in Fig. 5A and B.

\section{UV-visible study}

Fig. $7 \mathrm{~S} \dagger$ shows the effect of cobalt nitrate on the spectrum of RAB sodium. The shift in the wavelength indicates the presence of possible complexation reaction between RAB sodium and cobalt.

To increase the analytical performance of the proposed methods, a comparison with other reported methods was conducted (Table 4). Clearly, the proposed methods are simple with more sensitive results in terms of LOD and LOQ than those of the reported methods.

\section{Reaction mechanism}

The suggested electrochemical oxidation of the studied RAB sodium by CV and SWAdSV is described in Scheme 1. This is based on the electrochemical data described and supported by the RAB sodium structure; first, a coordinate complex between RAB sodium and cobalt form, and then loss of an electron likely occurs on the aromatic ring, where the extent of conjugation is greater, making the removal of an electron easier. One electron is removed from one molecule, followed by deprotonation to produce a cation radical, which reacts with water and leads to the formation of the hydroxylated species. ${ }^{34,35}$

\section{Conclusion}

In this study, a pencil graphite electrode was applied for the first time as a sensitive electrochemical sensor for the direct determination of RAB sodium. Cyclic voltammetry and square-wave adsorptive voltammetry were used for the deeper investigation of the electrochemical behavior of RAB sodium and its quantification in the tablet dosage form and spiked human urine samples. Clearly, the proposed electroanalytical methods are considerably time saving, economical, and highly sensitive without any chemical modification of the electrode surface. The method is sufficiently selective because the common excipients and urine constituents did not interfere with the sensing capabilities under these conditions. This simple, rapid, and inexpensive procedure could be a good alternative to other analytical approaches for the pharmacokinetic and pharmacodynamic purposes and effective determination of RAB sodium in the biological samples. Considering the results obtained in this study, the PGE may find future applications as a sensitive electrochemical sensor in the drug analysis.

\section{Notes and references}

1 G. L. Patrick, An introduction to Medicinal Chemistry, Oxford, USA, 4th edn, 2009, vol. 25, pp. 653-680.

2 A. El-Gindy, F. El-Yazby and M. M. Maher, J. Pharm. Biomed. Anal., 2003, 31, 229-242.

3 M. E. El-Kommos, P. Y. Khashaba and M. M. El-Wekil, Asian J. Biomed. Pharm. Sci., 2013, 3, 31.

4 M. A. S. Moneeb, Pak. J. Pharm. Sci., 2008, 21, 214-224.

5 M. E. El-Kommos, P. Y. Khashaba and M. M. El-Wekil, Int. J. Pharm. Pharm. Sci., 2014, 6, 212.

6 M. Noubarani, F. Keyhanfar, M. Motevalian and M. Mahmoudian, J. Pharm. Pharmaceut. Sci., 2010, 13, 1-10.

7 E. Simpemba, R. Liu, C. Sun, J. Engelbert and A. L. Ding, J. Sep. Sci., 2014, 37, 1951-1956. 
8 C. Lua, Y. Jiaa, Y. Songa, X. Lia, Y. Suna, J. Zhaoa, S. Wanga, L. Shic, A. Wena and L. Dingb, J. Chromatogr. B: Anal. Technol. Biomed. Life Sci., 2015, 988, 75-80.

9 N. V. S. Ramakrishna, K. N. Vishwottam, S. Wishu, M. Koteshwara and S. Suresh Kumar, J. Chromatogr. B: Anal. Technol. Biomed. Life Sci., 2005, 816, 209-214.

10 T. Uno, N. Y. Furukori, M. Shimizu, K. Sugawara and T. Tateishi, J. Chromatogr. B: Anal. Technol. Biomed. Life Sci., 2005, 824, 238-243.

11 A. Radi, N. Abd El-Ghany and T. Wahdan, Il Farmaco, 2004, 59, 515-518.

12 R. L. McCreery, Carbon electrodes: structural effects on electron transfer kinetics, in Electroanalytical Chemistry, ed. A. J. Bard, Marcel Dekker, New York, 1991, p. 18.

13 K. Kalcher, J. M. Kauffmann, J. Wang, I. Svancara, K. Vytrans, C. Neuhold and Z. Yang, Electroanalysis, 1995, 7, 5-22.

14 M. E. Rice, Z. Galus and R. N. Adams, J. Electroanal. Chem., 1983, 143, 89-102.

15 D. Blum, W. Leyffer and R. Holze, Electroanalysis, 1996, 8, 296-297.

16 H. Karademiz, B. Gulmez, F. Sadinci, A. Erdem, G. I. Kaya, N. Uncer, B. Kivcak and M. Ozsoz, J. Pharm. Biomed. Anal., 2003, 33, 295-301.

17 J. Wang and A. N. Kawde, Anal. Chim. Acta, 2001, 431, 219224.

18 L. Engel and W. Baumann, Fresenius' J. Anal. Chem., 1993, 346, 745-751.

19 P. Masawat, S. Liawruangrath, Y. Vaneesorn and B. Liawruangrath, Talanta, 2002, 58, 1221-1234.
20 A. M. Bond, P. J. Mahon, J. Schiewe and V. Vicente-Beckett, Anal. Chim. Acta, 1997, 345, 67-74.

21 D. King, J. Friend and J. Kariuki, J. Chem. Educ., 2010, 87, 507-509.

22 J. K. Kariuki, J. Electrochem. Soc., 2012, 159, 747-751.

23 N. Chauhan, J. Narang and C. Pundir, Am. J. Anal. Chem., 2010, 2, 41-46.

24 D. Demetriades, A. Economou and A. Voulgaropoulos, Anal. Chim. Acta, 2004, 519, 167-172.

25 K. Pokpas, S. Zbeda, N. Jahed, N. Mohamed, P. G. Baker and E. I. Iwuoha, Int. J. Electrochem. Sci., 2014, 9, 736-759.

26 M. Vestergaard, K. Kerman and E. Tamiya, Anal. Chim. Acta, 2005, 538, 273-281.

27 Y. W. Hartati, S. Topkaya, I. P. Maksum and M. Ozsoz, Advances in Analytical Chemistry, 2013, 3, 20-27.

28 M. Cousta Sousa and J. W. Buchanan, Comput. Graph. Forum, 2000, 19, 27-49.

29 N. Kurra and G. U. Kulkarni, Lab Chip, 2013, 13, 2866-2873.

30 P. Y. Khashaba, H. R. H. Ali and M. M. El-Wekil, Electroanalysis, 2016, DOI: /10.1002/elan.201600639.

31 A. J. Bard and L. R. Faulkner, Electrochemical Methods, Fundamentals and Applications, Wiley, New York, 1980.

32 E. Laviron, J. Electroanal. Chem., 1979, 10, 19-28.

33 J. C. Miller and J. N. Miller, Statistics for analytical chemistry. Ellis Horwood Series, PTR Prentice Hall, New York, London, pp. 119-121.

34 F. Salama, N. El-Abasawy, S. A. Abdel Razeq, M. M. F. Ismail and M. M. Fouad, J. Pharm. Biomed. Anal., 2003, 33, 411-421.

35 S. M. A. Jorge, A. D. R. Pontinha and A. M. Oliveira-Bretta, Electroanalysis, 2010, 22, 625. 